\title{
ICT, Permeability Between the Spheres of Life and Psychological Distress Among Lawyers
}

\author{
Nathalie Cadieux \\ Business school \\ University of Sherbrooke \\ nathalie.cadieux@usherbrooke.ca
}

\author{
Elaine Mosconi \\ Business school \\ University of Sherbrooke \\ elaine.mosconi@usherbrooke.ca
}

\author{
Nancy Youssef \\ Business school \\ University of Sherbrooke \\ nancy.youssef@usherbrooke.ca
}

\begin{abstract}
The pervasiveness of information and communications technologies (ICT) has changed the nature of work in recent decades. Positive and negative impacts of ICT have been identified in every profession, including among lawyers. This paper examines the impact of ICT on the working conditions, stress and psychological distress experienced by lawyers, based on a qualitative study. Twenty-two (22) interviews were conducted with the aim of gaining a deep understanding of this issue. A thematic content analysis of the interviews revealed that factors related to ICT appear to contribute to the overall stress (technostress and other stress) experienced by lawyers, in turn leading to psychological distress. Moreover, the growing permeability between the different spheres of life caused by ICT and their particular characteristics has increased the workload of lawyers and accelerated their pace of work. Participants also identified frequent technological problems, as well as clients' misinformation on the Internet, as risk factors.
\end{abstract}

\section{Introduction}

Although new technologies make day-to-day work easier, they also accelerate the pace of work [1] and induce conflicts between the different spheres of life (e.g., work and family), making them increasingly permeable to each other $[2,3]$.

This is particularly true in the knowledge-based economy and in the context of the intensification of telework, where information and communication technologies (ICT) are now an integral part of professionals' lives [4]. According to a survey conducted in $2018,95 \%$ of adults in the US own a cellphone (77\% own smartphones) and 53\% own a tablet. Among adults with smartphones, $26 \%$ reported going online almost constantly, while $43 \%$ reported going online several times a day [5]. Moreover, organizations allow their members to use personal mobile devices on the company's network; $76.7 \%$ of respondents in a survey of over 500 executives at large companies in the US, UK and Germany confirmed this practice, known as bring your own device (BYOD). Indeed, $95 \%$ of companies participating in a Cisco IBSG survey across eight countries reported having a BYOD policy in place [6]. These practices expand the ways of reaching employees (technology intrusiveness) [3], increasing the permeability between the different spheres of their lives [3].

Thus, despite the positive effects of technological developments, particularly increased flexibility in the organization of work, the recent literature also demonstrates the deleterious and noxious effects of the use of ICT on workers' psychological health [7].

Better known as "technostress", this phenomenon is defined as the inability to adjust to the constraints induced by ICT [8], thus leading to health problems, including psychological distress at work. It is also defined as all the negative direct or indirect effects of the use of ICT on individuals' attitudes, behaviors or psychological health $[9,10]$.

When added to the stress already present in the workplace, technostress increases the risk of psychological distress. In Canada, mental health problems are among the most costly medical conditions, representing an annual tax burden of over $\$ 50$ billion and $2.8 \%$ of GDP (CSMC, 2013). The same phenomenon can be observed in the United States and the European Union, where the annual costs associated with mental health problems are $\$ 200$ billion and $€ 20$ billion, respectively [11].

Beyond these statistics, some professionals do indeed appear to struggle with these issues. Studies have shown that lawyers are among the occupational groups with the highest risk of burnout or other stress-related problems, including anxiety, depression, substance abuse and suicide. [12-14]. In the province of Quebec (Canada), lawyers face these problems. Although no 
study has investigated the work-related distress rate among lawyers in Quebec, over 10,700 requests for assistance have been made to the lawyer's assistance program in this province (PAMBA) over the last 20 years [15]. Over 1,000 such requests were made in 2016, compared to 296 in 2004 [15].

Current contextual factors make lawyers a relevant sample of professionals when it comes to gaining a deep understanding of technostress and its impacts. First, the technological developments of recent decades have considerably transformed the practice of law and contact with clients. An accelerated work pace, combined with increased accessibility, have added to the stressors already present in the work environment of lawyers. Second, leading law firms and the Canadian government have made major investments in recent years aimed at advancing the development of artificial intelligence, with the goal of enabling robots to perform some tasks traditionally performed by lawyers [16]. Thus, lawyers will likely increasingly interact with technology in the coming years, heightening the risk of experiencing technostress. This article examines the impact of the use of ICT on the working conditions, stress and psychological distress experienced by lawyers, based on a qualitative study. By using a semi-inductive approach and involving a continuous iterative thematic content analysis of rich data from semi-structured interviews with 22 lawyers, some common dimensions emerged. The findings highlight the various advances in technology and its uses that contribute to the level of technostress, other stress and psychological distress experienced by these professionals. The results helped bring out a theoretical model explaining technostress as experienced by lawyers, while drawing a portrait of the mechanisms through which these developments contribute to psychological distress.

\section{Theoretical background}

ICT are sources of efficiency, productivity, agility and flexibility, allowing for the enhancement of business performance. They help improve operations and positively impact communication, information management and many other aspects of organizations [7, 17-20].

Employees now have easier access to the information they need, anywhere and at any time, through technological developments such as smart phones and laptops. [17, 21]. Furthermore, employees can now accomplish their tasks without spatial or temporal constraints through IT-enabled remote work, referred to as "telework" [17].

When ICT were first introduced into organizations, the flexibility they afforded was seen as facilitating the reconciliation of individuals' work and personal lives [22]. Employees had a positive perception of ICT, considering them to be useful in improving their ability to perform tasks faster and be more productive [23] and flexible [3].

However, while technological advances have helped professionals carry out their day-to-day work more efficiently, they can also negatively affect people's cognitive, psychological and physical health [7, 24, 25]. It is becoming difficult for employees to distance themselves from work during off time because of their dependence on these technologies [26]. The BYOD practices adopted by many organizations are also increasing the intrusiveness of ICT, since employees can be reached at any time [3]. Furthermore, excessive dependency on ICT and the constant need to adapt to emerging IT applications have been found to increase the level of stress caused by these technologies [21].

This phenomenon, known as "technostress," is defined as the inability to adjust to the constraints induced by ICT [8], thus leading to health problems, including psychological distress at work, as well as decreased job satisfaction [17, 23, 24, 27].

The recent literature on technostress has provided insight into this phenomenon, bringing out a clear distinction between the antecedents of technostressors (e.g., ICT characteristics [23] and job characteristics [17]), the sources or creators of technostress, referred to as technostressors [23, 27], and the implications or consequences of technostress (i.e., low productivity, dissatisfaction at work, lack of job involvement, and poor job performance [27]; short-term exhaustion to long-term physiological, social, and/or psychological harm [28], and strain [23]). Based on their investigation of this phenomenon, Ayyagari, Grover and Purvis [23] proposed a theoretical framework explaining it.

\subsection{Ayyagari, Grover and Purvis's model}

Ayyagari, Grover and Purvis's model [23] illustrates the process through which ICT characteristics contribute to the development of technostress. According to this model, these characteristics directly influence five main technostressors, which in turn influence technostress. ICT characteristics refer to the usability, intrusive and dynamic features of these technologies [23].

Usability features refer to the usefulness, complexity and reliability of ICT, which influence their adoption but can also increase an individual's workload. Despite having a low perception of the usefulness and reliability of ICT and a negative perception of their complexity, today's professionals have no choice but to adopt them $[9,23]$. 
Intrusive features refer to the constant connectivity induced by ICT, and specifically to presenteeism and anonymity [23]. Presenteeism is directly related to the fact that these technologies make people more reachable outside working hours through the use of laptops, cellphones, the Internet, and so on. The use of these collaborative technologies is traceable and exposes individuals to various problems related to anonymity [23].

The dynamic features of ICT refers to the constant and rapid changes that emerge in these technologies. These changes require constant adaptation, which can have an impact on an individual's workload. The adoption of new ICT requires employees "to solve technical issues while simultaneously learning and using new IT tools" [17]. Studies have shown that strain is influenced by particular stressors, the most important being work overload and role ambiguity, which are related to the intrusiveness of ICT [23].

Each of these characteristics influences technostressors. Technostressors refer to work-home conflict, the intrusion of privacy, role conflict or role ambiguity, work overload and job insecurity [23]. According to this model, these technostressors lead to technostress, a relationship explained by the transactional theory of stress $[29,30]$. This theory explains the process through which the stress generated by a work situation is the result of a complex and subjective "transaction" between an individual and his or her work environment [30-34]. Thus, stress does not stem solely from the technostressor or the individual him or herself, but rather from the individual's response to stress, the result of a dynamic process involving the individual's resources [35, 36]. An individual's level of technostress is thus subjective and constantly subject to change, depending on a close interaction between these factors.

\subsection{Conceptual gap and aims of this study}

Despite recent gains in knowledge on technostress, several gaps remain. First, although several authors have highlighted the impact of technostress on psychological health at work [7, 23], this impact has not been evaluated directly. Second, current models fail to identify and explain the mechanisms through which technostress leads to psychological distress at work. Finally, in our view, another key problem is that the technostressors currently identified in the literature are stressors that exist independently of ICT, although ICT can exacerbate them. Work-home conflict, role conflict, role ambiguity, work overload and job insecurity are workplace stressors that can emerge regardless of the presence of ICT. It is thus important to identify the specific contribution of ICT to these stressors as well as the mechanisms though which they contribute to technostress.

This study addressed these gaps, focusing on the impact of ICT on technostress and psychological distress among lawyers in Quebec. Using Ayyagari et al.'s model [23] as a starting point, it clarified some aspects of this model using a semi-inductive approach. More specifically, its main goals were twofold. First, it aimed to gain an understanding of the mechanisms through which technostress leads to psychological distress (physical, psychological and behavioral symptoms [37]). Second, it aimed to evaluate the extent to which the participants attributed their stress to the technostressors identified by Ayyagari et al. [23], while noting their symptoms of psychological distress, albeit without a clinical diagnosis. These two goals led to a third goal, which was to identify the specific contribution of ICT to technostressors and, in turn, to the overall level of stress among participants.

\section{Method}

This paper is based on qualitative data collected through face-to-face semi-structured interviews conducted in 2016 with lawyers in the province of Quebec (Canada). Given the lack of studies on the specific contribution made by technostress to symptoms of psychological distress at work, and by the technostressors identified by Ayyagari et al. [23] to technostress, a semi-inductive qualitative approach was chosen.

The interview questions used for the data collection consisted of five blocks of open-ended questions (14 questions) derived directly from our literature review, as well as a pre-test conducted at the start of the data collection, which allowed us to adjust the content of the interview guide.

\subsection{Participants}

Twenty-two (22) participants were involved in this study. They included women (14) and men (8) from Quebec bar associations who were self-employed, associates or employees, working in the private (15) and public (7) sectors, with an average of 16.3 years in various fields of practice. The participants were recruited in partnership with the Quebec Bar, which sent a description of the study as well as the principal researcher's contact information to the members of the bar associations concerned. Lawyers wishing to participate in the study then contacted the research team directly.

Since the main goal of this study was to identify the determinants of psychological distress among Quebec 
lawyers, participants were not chosen randomly, but rather selected by reasoned choice [38]. The main criteria for inclusion were to be practicing law and to have been a member of the Quebec Bar for at least 12 months. To ensure the heterogeneity of the sample, no more than two lawyers representing the same firm could participate in the study. The total number of participants was determined when empirical and theoretical saturation was reached [38-41]. The participants' average age was 43 and they were working between 40 and 80 hours per week (average of 54 hours/week).

\subsection{Data analysis}

The semi-structured interviews were recorded and then fully transcribed. A thematic content analysis of the interviews was performed using QDA Miner 4. This qualitative analysis software facilitates the management of data and counts the occurrence of codes and categories. The coding process was performed as the data were collected, making it possible to determine when theoretical and empirical saturation had been reached [38].

The analysis took place in 5 phases based on the work of Creswell [42]. However, given the semiinductive research approach used, the coding was based on a list of ICT characteristics, technostressers and symptoms of psychological distress drawn from the literature review, which was then enriched during the coding process. This analytic strategy was carried out iteratively [43]. Each step was repeated until the typology stabilized, that is, until no new interviews produced new or relevant data regarding the categories, the categories were well developed, and the relationships between the categories had been thoroughly validated, thus confirming that theoretical and empirical saturation had been reached [44, 45].

A diary and codebook were also kept throughout the data collection process. To ensure the internal validity of the research, a randomly selected interview sample was coded by two different researchers, including an expert, and then subjected to multiple coding. Through comparison and discussion, multiple coding provides a common and unambiguous view of the meaning of codes between two researchers, ensuring consistency in the data and codes [38]. This type of coding makes it possible to obtain clearer code definitions and leads to better reliability. The transcripts were then carefully coded a second time by the other researcher, and the final codes were compared and classified [43].

The coding process and final coding of the transcripts were validated by an expert to ensure their credibility. Finally, to confirm the validity of the conclusions reached, the results of the analyses were presented to three different focus groups of lawyers from different practice settings who did not participate in the study.

\section{Results}

All 22 participants reported experiencing stress related to ICT (technostress) throughout their careers. Participants explained a part of this technostress by the fact that ICT added to the existing conflicts between their work lives and personal lives, in particular by increasing the permeability between these different spheres. Technostress compounded the stress generated by other stressors, as noted by Ayyagari et al. [23], ultimately leading to psychological distress.

Based on the frequencies of the codes related to each category of stress reported by the participants, the proportion of technostress (e.g., stress due to ICT) was calculated to be $32 \%$ (58 occurrences) compared to $68 \%$ (124 occurrences) for other stress as shown in Figure 1.

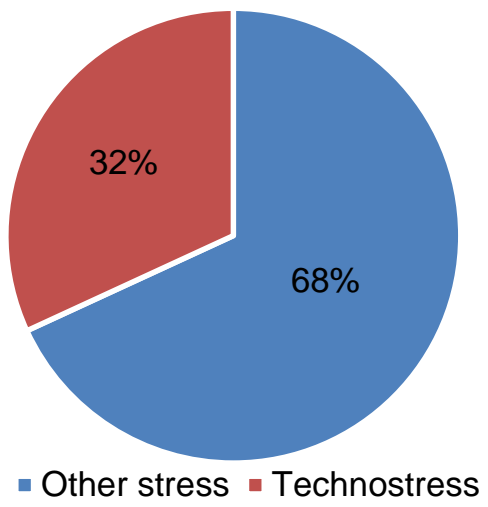

Figure 1. Proportion of technostress compared to other stress reported by participants

A total of 21 of the 22 participants reported symptoms of psychological distress (211 occurrences). Psychological distress entailed three types of symptoms: physical symptoms (e.g., fatigue), psychological symptoms (e.g., anxiety) and behavioral symptoms (e.g., absenteeism).

The participants reported that the characteristics of ICT, namely their usability, intrusive and dynamic features, reduced the clear separation between the different spheres of their lives. Consequently, the participants were never completely immersed in the personal sphere or work sphere, since ICT, and their intrusive features, made them constantly reachable. The increased permeability between these spheres compounded the stressors already present in their working environment (e.g., work hours, work demands).

This permeability also exacerbated technostressors such as work overload, work-home conflict, the 
invasion of privacy, role-ambiguity and job insecurity. Figure 2 presents the frequencies of each technostressor as reported by the interviewees. In addition to the technostressors identified by Ayyagari et al. [23], our coding process brought out a new technostressor, the increased pace of work, which amplified the pressure exerted on lawyers. This technostressor ranked third (16 occurrences) among the technostressors identified, following work overload (26 occurrences) and workhome conflict (22 occurrences).

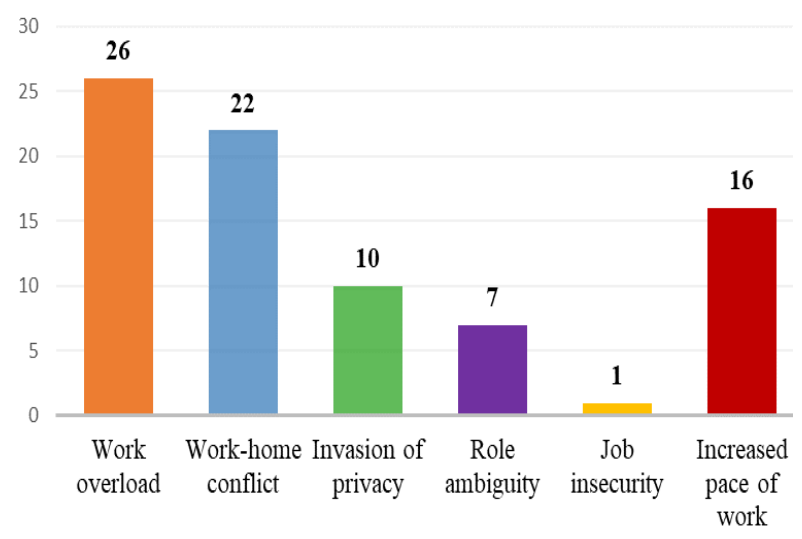

Figure 2. Frequencies of codes for each technostressor observed

\subsection{Impact of ICT characteristics on stress and technostress}

Table 1 presents the frequencies of the codes for each ICT characteristic, overall stress (technostress and other stress) and psychological distress.

Table 1. Technostress, other stress, symptoms of psychological distress and ICT characteristics

\begin{tabular}{|c|c|c|}
\hline & Codes & Frequencies \\
\hline \multirow[t]{2}{*}{ Overall stress } & $\begin{array}{c}\text { Technostress (stress } \\
\text { due to ICT) }\end{array}$ & 58 \\
\hline & Other stress & 124 \\
\hline $\begin{array}{c}\text { Psychological } \\
\text { distress }\end{array}$ & $\begin{array}{c}\text { Symptoms of } \\
\text { psychological distress }\end{array}$ & 221 \\
\hline \multirow{3}{*}{$\begin{array}{l}\text { Usability } \\
\text { features }\end{array}$} & Usefulness & 43 \\
\hline & Complexity & 10 \\
\hline & Reliability & 19 \\
\hline \multirow{2}{*}{$\begin{array}{l}\text { Intrusive } \\
\text { features }\end{array}$} & Presenteism & 98 \\
\hline & Anonymity & 6 \\
\hline $\begin{array}{l}\text { Dynamic } \\
\text { features }\end{array}$ & Pace of change & 5 \\
\hline
\end{tabular}

The findings show that an intrusive feature of ICT, presenteeism, was the most pervasive phenomenon among lawyers, with 98 occurrences. Consequently, intrusive features ranked first among ICT characteristics in terms of contributing to the permeability between the different spheres of life, followed by usability features, and then dynamic features.

To distinguish technostress from other types of stress, each occurrence was counted as technostress only when the participant attributed it to ICT. Occurrences wherein the participant felt stressed, but not due to ICT, were classified under other stress. Occurrences of psychological distress (physical, psychological or behavioral symptoms) were also noted only when the participant reported stress and linked them to ICT (technostress).

4.1.1. Impact of usability features. The usability features of ICT lead people to massively adopt communication tools (e.g., smartphones or email) and then expect others to do the same. As a result, clients who have embraced these technologies in recent years expect their lawyers to be more responsive. If they send an email and their lawyer does not respond within the hour, they will send it again, seeking to receive an immediate answer, as explained by some interviewees:

"Now we've moved to the computer age where we have email. So you have to respond quickly, because people use it. 'You can send it to me by email.' Email has accelerated the pace of work. But not the pace of our thoughts! So people send you an email at 9:00 a.m., and at 2:00 p.m. they send you a reminder, because they don't understand why you haven't answered them."

This pressure from clients due to the usability features of ITC increases the pace of work for lawyers, as many of them mentioned:

"There's always more, it's always faster ... Because, I think ... technology has made everything faster."

"Today we do a day's work in 3 or 4 hours. Because the understanding is that ... you'll ask me by email and I'll answer you, and then you'll answer me again in half an hour, since you'll have your computer or smartphone in front of you and will be checking it. If things don't go quickly, you'll address it, send another message ... And this creates a problem ... a lot of pressure."

Among the usability features, the reliability of ICT also contributes to the workload of lawyers.

"And then emails, of course, in the morning ... My inbox is always full of new emails and it keeps filling up as I empty it"

Constant connectivity causes frequent interruptions and limits productivity, as illustrated by the comments of one interviewee:

"I was very irritable, very tired... exhausted ... The phone was ringing and I found myself thinking, "What bleeping problem do they have now? I couldn't do my job." 
In addition, the advances in technology and accessibility of information on the Internet have led some clients to obtain information directly from websites before contacting a lawyer, even though this information can be wrong. This raises the level of clients' demands or leads them to dispute the professional expertise delivered by the lawyer. The lawyer's workload is thus increased, contributing to the level of technostress, as work overload is an important technostressor. This is illustrated by the following excerpt:

"And the clients, compared to clients 20 years ago ... look things up on the Internet, and say: I found 12 cases like mine and they all won. Yeah, right! 12 cases like yours, same case, same place, same people, same city, same judge ... my answer? No way."

Paradoxically, the accessibility of information has also increased the workload of lawyers, as clients are increasingly informed through the Internet, creating a pressure for lawyers to engage in continuous learning and skill development to keep up with client expectations:

"There are more and more demands because clients are more and more informed ... with the Internet, with all the information they have access to ... So, you have to update your skills ... your client has probably communicated with this guy and that guy and this other guy, and arrives with a list of questions ... And you have to provide answers to all these questions."

Moreover, with regard to the reliability characteristic of ICT, the participants reported experiencing a high number of technical problems, which were an important source of stress.

"There's always something that doesn't work. [laughs] It's constant! ... It's a major irritant for me."

"All the technical problems we experience, it's a waste of time! It's crazy! The computer, the phone, the photocopier... If we could make sure that everything worked all the time, we'd be ... more productive. It's a stupid source of stress."

These problems added to the constraints experienced by the participants (e.g., lack of time, deadlines), while increasing their work hours.

"So, there are all these problems together, and sometimes you say, "ok, I'm not going to photocopy that, I'll do it tonight when I have 2 minutes to see how it works. "Sometimes that's why I'm here at night."

4.1.2. Impact of intrusive features. The usability and functionality of these technological tools (e.g., smartphones that can receive emails) end up leading to significantly longer workdays, contributing to the impact of the intrusiveness of ICT. Indeed, when lawyers leave work, they continue to receive e-mails and answer them, sometimes until very late at night:
"Well, first they gave us smartphones ... that can receive emails [laughing] ... I put them on a different page on my phone so I won't see them, because ... You know, sometimes I say, 'ah! I shouldn't look at them' and then ... just before going to bed, I know it's dumb, but I look at them. Then I go to bed and I'm like "Well, there's this case, there's that case ... there's just no break."

The ease of communication and ability to connect with people anywhere and at any time, related to the usability features of ICT and their intrusiveness, increases the permeability between the different spheres of life. This leads to work-home conflict. Indeed, most participants reported receiving calls and emails from clients outside working hours. Having a smartphone that is used for both personal and work purposes makes it difficult for lawyers to detach themselves from work. Two participants stated that they chose not to have smartphones to avoid this invasion of their privacy and added workload.

"I don't have a cell phone for this reason. Well, I have one, but I never use it."

It thus appears that the advent of ICT has led to a major change in how the legal profession works. The participants explained that their relationship with clients is now closer than in the past.

"Because of ICT, our relationship with clients has become, with smart phones and everything, we're really in direct contact with clients all the time ... It's more ... The profession is more related to that now, to service."

The usability features of ICT for clients thus lead to intrusive features such as presenteeism for lawyers, who have to respond to phone calls anywhere and at any time:

"Sorry, there goes my phone again ... Huh! That's something else you learn when you're a lawyer. The phone ringing all the time."

These results add to the existing literature on these subjects $[2,3,13,23,26,28]$.

4.1.3. Impact of dynamic features. The dynamic nature of ICT was highlighted as a challenge that lawyers face on a day-to-day basis. It also leads to role ambiguity, work overload and stress.

"That's apart from all the challenges I would call technological. Technology is constantly changing. So you're regularly called on to do all kinds of tasks, as basic as using the photocopier. Or setting up your phone service. Switching phone companies is hell. Changing computers is hell. Changing photocopiers? Never mind! ... If it were just a question of those small ... 4 in 1 models, it wouldn't be complicated. But it's not that any more. If you want to work, you need a good computer, and it's not always easy to understand." 
Furthermore, since the technology is constantly changing and developing, the characteristics of work are also changing, adding to role ambiguity and work overload [21]. "They want me to give a course this fall, what they call a "webinar." It's a seminar given over the Internet that I'm going to work on this summer. So ... I'm planning that."

\section{Discussion, contributions and updated conceptual model}

First, our results tend to confirm the contribution to technostress made by the ICT characteristics and technostressors identified by Ayyagari et al. [23], while also bringing out their contribution to psychological distress. Although several authors have highlighted the importance of studying the impact of technostress on psychological health $[7,23]$, no other studies to date have explored this relationship. This is thus the first study aiming to link technostress to psychological distress, which is an important contribution of this paper. Moreover, our results also confirm other consequences of technostress reported in the literature (i.e., low productivity, dissatisfaction at work, lack of job involvement, and poor job performance [27]; shortterm exhaustion to long-term physiological, social, and/or psychological harm [28], and strain [23]).

A second contribution of our study is that it clearly distinguished stress stemming from ICT (technostress) from other types of stress, unrelated to ICT. During the data analysis, each occurrence was labeled as technostress only when the participant reported being stressed because of ICT. While some authors, including Ayyagari et al. [23], have considered the importance of this distinction, more recent studies on technostress have not, leading to potential tautological and redundancy issues. A third contribution of the present study is that it identified the increasing pace of work as an additional technostressor, to be added to those identified by Ayyagari et al. [23].A fourth contribution of this qualitative study is the extensive and rich data and analysis it provides. The interviews revealed that ICT characteristics do not directly influence technostressors, as postulated by Ayyagari et al. [23]. Rather, these characteristics (usability, intrusive, and dynamic features) influence the permeability between the different spheres of life, as mentioned by other authors $[2,3,13]$. Combined, these features create a greater effect than when each is considered in isolation. They exacerbate the stressors already present in the various spheres of life, contributing to technostressors such as work-home conflict. Moreover, each of these characteristics, particularly the intrusive ones, increase the permeability between the different spheres of life [2, 13]. This permeability is defined as an interaction zone wherein the stressors stemming from each sphere of life influence each other.

Finally, this study provides insight on the role played by technostress in psychological health, as illustrated in the updated model presented in Figure 3.

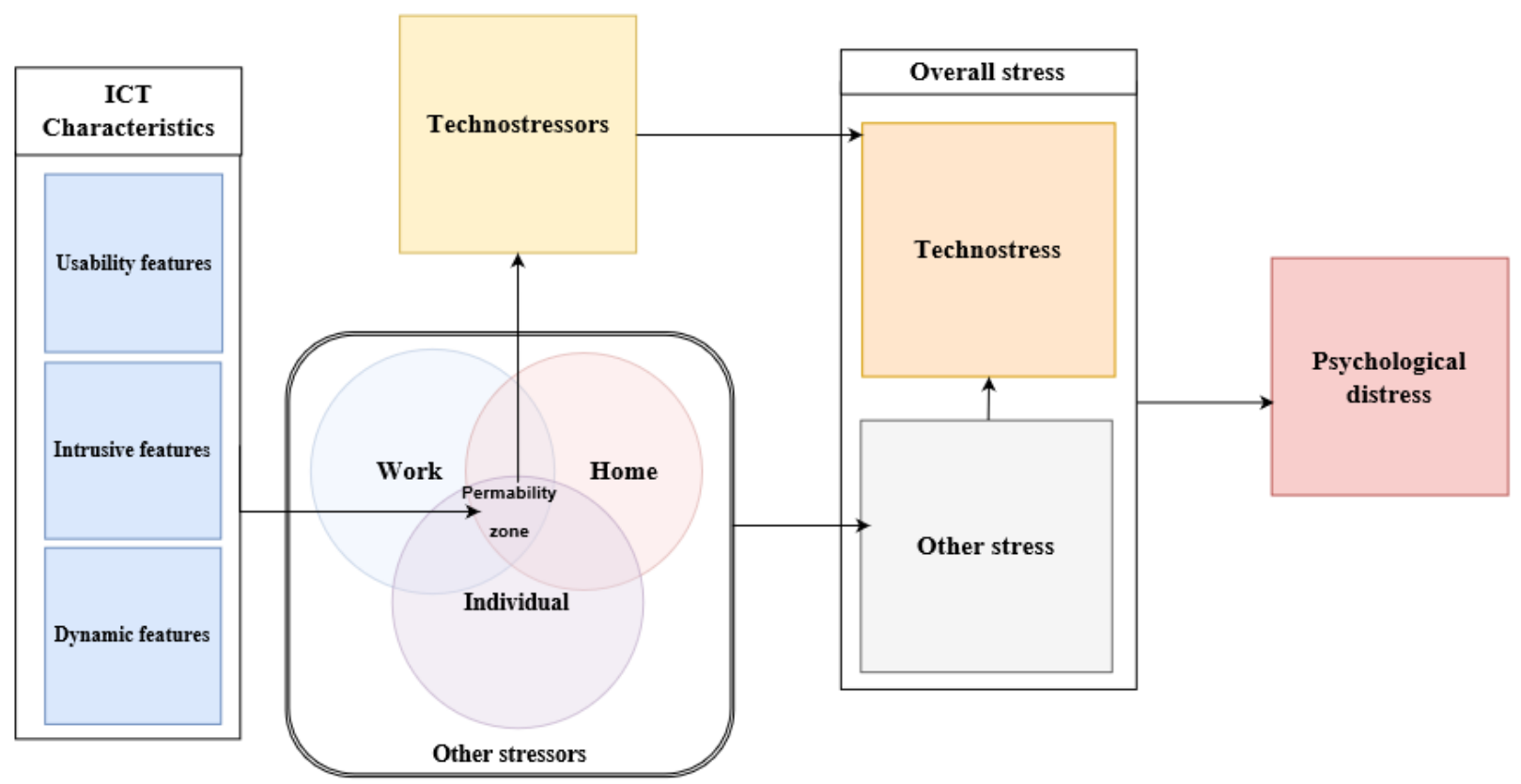

Figure 3. Updated conceptual model explaining the relationship between ICT characteristics, technostressors, technostress and psychological distress 
The new model illustrates that other stressors emerge from different spheres of life (work, family, and personal life) [46, 47]. Based on our analysis, this updated model postulates that the constraints and resources available to an individual, which are likely to exacerbate or reduce overall stress and psychological distress, do not come solely from the work, family, or personal spheres, but rather from a combination of factors derived from these spheres and the interaction between them [46]. The permeability between these spheres is increased by the characteristics of ICT, particularly their intrusive features. In turn, this permeability exacerbates technostressors such as workhome conflict or the invasion of privacy $[23,28]$. This relationship can be seen to operate in relation to various stressors such as work hours [13, 48, 49] or parental responsibilities [13]. ICT, through their intrusiveness, made the participants more reachable, extended their work hours and blurred the boundaries between the different spheres of their lives. For example, many lawyers worked several hours a week beyond their normal working hours, because ICT made it possible to deal with e-mails at home. If they had dependent children, they would be more likely to experience workhome conflict, an important technostressor for lawyers $[13,50]$. In this dynamic process, involving an individual's resources, technostressors and technostress (stress due to ICT), together with other stressors already present in an individual's environment, can affect the individual's capacity to face stress and ultimately lead to psychological distress [30, 31, 33, 34, 36, 51, 52]. These technostressors are exacerbated by the permeability between the different spheres of life. In addition to the technostressors identified by Ayyagari et al. [23], our coding process added a new technostressor, namely an increase in the pace of work.

Our conceptual model illustrates that technostressors generated by the permeability between the different spheres of life lead to technostress, which, when combined with stress generated by other stressors, contributes to psychological distress at work and affects an individual's unconscious psychological reaction when facing stressful situations.

\section{Conclusion and limitations}

The main purpose of this paper was to examine the impact of information and communication technologies (ICT) on the working conditions, stress and psychological distress experienced by lawyers, based on a qualitative study. Our results suggest that the use of ICT constitutes a risk factor for stress and psychological distress among lawyers in Quebec.
As illustrated in our updated conceptual model, our findings show that ICT characteristics contribute to stress through increased permeability between the different spheres of life, exacerbating stressors such as work-home conflict. These findings are in line with those of Ayyagari et al. [23], who investigated the contribution to overall stress of stressors such as workhome conflict and role ambiguity. Using a qualitative approach, our study investigated how technostress and other types of stress contribute to overall stress and psychological distress among lawyers in Quebec.

Our findings were based on rich data from a specific context and offer a relevant and in-depth understanding of technostress and psychological distress among lawyers. They present a basis for further research on this subject. Despite the limitations of the present study due to the use of a qualitative methodology, this paper illustrates the mechanisms through which ICT characteristics contribute to the level of overall stress (technostress and stress), ultimately leading to psychological distress. However, further research involving a larger sample is needed to generalize the incidence of the factors identified in this study. For example, which factors are the most important in terms of explaining why ICT create stress? And how can these effects be mitigated? Although our results highlight the role played by the increased permeability between the different spheres of life in the development of technostress, the qualitative nature of this study does not allow us to confirm this assumption. A future quantitative study is needed to validate whether the interaction between the stressors stemming from the different spheres of life are responsible for the development of technostress and confirm that the relationship between ICT characteristics and technostress is not direct, as originally postulated by Ayyagari et al. [23]. Recent research has shown that social networking sites and social media platforms improve work-related outcomes and decrease work isolation, thus increasing positive emotions and work satisfaction, while decreasing work stress. This, in turn, leads to a decrease in turnover intentions [53]. In addition, new ways to mitigate technostress have been investigated, taking into account dimensions outside of work [54]. More recently, IT mindfulness, a dynamic IT-specific concept based on four dimensions: alertness to distinction, awareness of multiple perspectives, openness to novelty and orientation in the present, has been shown to mitigate the effects of technostress [55].

\section{Future implications}

Following up on the results of this study, the quantitative phase of a major research project aimed at 
validating the updated conceptual model has already been planned for 2019, in partnership with the Quebec Bar.

This project will include the contribution of stressors from different spheres of life, including the personal sphere. It will measure the impact of personality traits as well as certain skills, such as psychological detachment, assertiveness and coping, and their interaction with other stressors (e.g., work hours), on the development of technostressors such as work-home conflict. Moreover, although the results of the present study showed a low prevalence of the technostressor "job insecurity," it will be relevant to re-evaluate this technostressor, as many Canadian law firms are investing in artificial intelligence with the aim of enabling robots to execute some tasks currently carried out by lawyers. This development is likely also emerging in other industrialized countries.

In addition to its academic implications, this study highlights some managerial implications related to the work environment. It is important to take into account the workload of employees and the pressures and new practices imposed on them through the use of ICT. The Quebec Bar could use our results to improve the work environment and some work-related measures in order to reduce the levels of stress and psychological distress experienced by lawyers.

Finally, other professions (e.g., engineers) will also eventually be investigated in order to validate the transferability of the results obtained for lawyers. This will help to bring out common determinants in different professions.

\section{References}

[1] M. P. O’Driscoll, P. Brough, C. Timms, and S. Sawang, "Engagement with information and communication technology and psychological well-being," New developments in theoretical and conceptual approaches to job stress, pp. 269-316: Emerald Group Publishing Limited, 2010.

[2] W. R. Boswell, and J. B. Olson-Buchanan, "The use of communication technologies after hours: The role of work attitudes and work-life conflict," Journal of Management, vol. 33, no. 4, pp. 592-610, 2007.

[3] T. Nam, "Technology use and work-life balance," Applied Research in Quality of Life, vol. 9, no. 4, pp. 1017-1040, 2014.

[4] A. Day, S. Paquet, N. Scott, and L. Hambley, "Perceived information and communication technology (ICT) demands on employee outcomes: The moderating effect of organizational ICT support," Journal of Occupational Health Psychology, vol. 17, no. 4, pp. 473-491, 2012.

[5] P. r. center. "mobile fact sheet," http://www.pewinternet.org/fact-sheet/mobile/.

[6] J. Bradley, J. Loucks, J. Macaulay, R. Medcalf, and L. Buckalew, "BYOD: A global perspective," Harnessing
Employee-Led Innovation", available online at http://www.cisco.com/c/dam/en_us/about/ac79/docs/re/B YOD_Horizons-Global.pdf(accessed March 15th 2017), 2012.

[7] L. Atanasoff, and M. A. Venable, "Technostress: Implications for Adults in the Workforce," The Career Development Quarterly, vol. 65, no. 4, pp. 326-338, Dec 2017.

[8] C. Brod, "Managing technostress: optimizing the use of computer technology," Personnel Journal, vol. 61, no. 10, pp. 753-757, 1982.

[9] M. M. Weil, and L. D. Rosen, Technostress: Coping with technology@work@home@play: Wiley New York, 1997.

[10] L. Chen, and A. Muthitacharoen, "An empirical investigation of the consequences of technostress: Evidence from China," Information Resources Management Journal, vol. 29, no. 2, pp. 14-36, 2016.

[11] A. Gintrac, "Le stress au travail, un état des lieux," Management \& amp vol. 41, no. 1, pp. 89-106, 2011.

[12] G. E. Bailly, "Impairment, the Profession and Your Law Partner," Me. BJ., vol. 15, pp. 96-106, 2000.

[13] S. B. Carter, "When the enemy lies within: Risk for professional burnout among family lawyers," American Journal of Family Law, vol. 20, no. 3, pp. 160-168, 2006.

[14] J. D. Kammeyer-Mueller, L. S. Simon, and B. L. Rich, "The psychic cost of doing wrong: Ethical conflict, divestiture socialization, and emotional exhaustion," Journal of Management, vol. 38, no. 3, pp. 784-808, 2012.

[15] Pamba, "Cumulatif des demandes d'aide à ce jour: 1995 à 2016," Pamba, 2016.

[16] A. Roy, "Intelligence artificielle : L'ère des robotsavocats," La presse, July 29, 2017, http://plus.lapresse.ca/screens/2251e4e5-f703-4abc-bb178b5f1e3be1e5_7C_ivphQhHsMyco.html.

[17] A. Suh, and J. Lee, "Understanding teleworkers' technostress and its influence on job satisfaction," Internet Research, vol. 27, no. 1, pp. 140-159, 2017.

[18] A. Tarute, and R. Gatautis, "ICT impact on SMEs performance," Procedia-Social and Behavioral Sciences, vol. 110, pp. 1218-1225, 2014.

[19] A. Ollo-López, and M. E. Aramendía-Muneta, "ICT impact on competitiveness, innovation and environment," Telematics and Informatics, vol. 29, no. 2, pp. 204-210, 2012.

[20] M. Govindaraju, and D. Sward, "Effects of wireless mobile technology on employee work behavior and productivity: An Intel case study," Designing ubiquitous information environments: Socio-technical issues and challenges, pp. 349-351: Springer, 2005.

[21] S. C. Srivastava, S. Chandra, and A. Shirish, "Technostress creators and job outcomes: theorising the moderating influence of personality traits," Information Systems Journal, vol. 25, no. 4, pp. 355-401, Jul 2015.

[22] E. L. Kelly, P. Moen, and E. Tranby, "Changing workplaces to reduce work-family conflict: Schedule control in a white-collar organization," American Sociological Review, vol. 76, no. 2, pp. 265-290, 2011.

[23] R. Ayyagari, V. Grover, and R. Purvis, "Technostress: technological antecedents and implications," MIS Quarterly, vol. 35, no. 4, pp. 831-858, Dec 2011. 
[24] M. Tarafdar, E. B. Pullins, and T. S. Ragu-Nathan, "Technostress: negative effect on performance and possible mitigations," Information Systems Journal, vol. 25, no. 2, pp. 103-132, Mar 2015.

[25] Q. Tu, K. Wang, and S. Qin, "Computer-related technostress in China," Association for Computing Machinery. Communications of the ACM, vol. 48, no. 4, pp. 77-81, Apr 2005.

[26] Y. Park, C. Fritz, and S. M. Jex, "Relationships between work-home segmentation and psychological detachment from work: the role of communication technology use at home," Journal of Occupational Health Psychology, vol. 16, no. 4, pp. 457-467, 2011.

[27] M. Tarafdar, Q. Tu, B. S. Ragu-Nathan, and T. S. RaguNathan, "The Impact of Technostress on Role Stress and Productivity," Journal of Management Information Systems, vol. 24, no. 1, pp. 301-328, 2007.

[28] M. Tarafdar, Q. Tu, and T. Ragu-Nathan, "Impact of technostress on end-user satisfaction and performance," Journal of Management Information Systems, vol. 27, no. 3, pp. 303-334, 2010.

[29] R. S. Lazarus, "Psychological stress and the coping process", 1966.

[30] R. S. Lazarus, and S. Folkman, Stress, appraisal, and coping, New York: Springer, 1984

[31] S. Ibrahim, P. Smith, and C. Muntaner, "A multi-group cross-lagged analyses of work stressors and health using Canadian National sample," Social science \& medicine, vol. 68, no. 1, pp. 49-59, 2009.

[32] E. Kendall, and H. Muenchberger, "Stressors and supports across work and non-work domains: The impact on mental health and the workplace," Work, vol. 32, no. 1, pp. 27-37, 2009.

[33] A. H. De Lange, T. W. Taris, M. A. Kompier, I. L. Houtman, and P. M. Bongers, "The relationships between work characteristics and mental health: Examining normal, reversed and reciprocal relationships in a 4-wave study," Work \& Stress, vol. 18, no. 2, pp. 149-166, 2004.

[34] J. De Jonge, M. M. Reuvers, I. L. Houtman, P. M. Bongers, and M. A. Kompier, "Linear and nonlinear relations between psychosocial job characteristics, subjective outcomes, and sickness absence: Baseline results from SMASH," Journal of occupational health psychology, vol. 5, no. 2, pp. 256-268, 2000.

[35] R. T. Lee, B. L. Lovell, and C. M. Brotheridge, "Tenderness and Steadiness: Relating Job and Interpersonal Demands and Resources With Burnout and Physical Symptoms of Stress in Canadian Physicians," Journal of Applied Social Psychology, vol. 40, no. 9, pp. 2319-2342, 2010.

[36] M. H. Kendall E., "Stressors and supports across work and non-work domains: The impact on mental health and the workplace," Work, vol. 32, no. 1, pp. 27-37, 2009.

[37] N. Cadieux, and A. Marchand, "Psychological distress in the workforce: a multilevel and longitudinal analysis of the case of regulated occupations in Canada," BMC public health, vol. 14, no. 1, pp. 808-820, 2014.

[38] M. B. Miles, and A. M. Huberman, Analyse des données qualitatives: De Boeck Supérieur, 2003.
[39] J.-P. Pourtois, and H. Desmet, Épistémologie et instrumentation en sciences humaines: Editions Mardaga, 2007.

[40] J. Saldaña, The coding manual for qualitative researchers: Sage, 2015.

[41] A. L. Strauss, M.-H. Soulet, J. M. Corbin, S. Emery, and M.-H. Soulet, Les fondements de la recherche qualitative: techniques et procédures de développement de la théorie enracinée: Academic Press/Saint-Paul, 2004.

[42] J. W. Creswell, Educational research: Planning, conducting, and evaluating quantitative: Prentice Hall Upper Saddle River, NJ, 2002.

[43] P. Paillé, "L'analyse par théorisation ancrée," Cahiers de recherche sociologique, no. 23, pp. 147-181, 1994.

[44] B. G. Glaser, and A. L. Strauss, Discovery of grounded theory: Strategies for qualitative research: Routledge, 2017.

[45] S. J. Tracy, "Qualitative research methods," UK: WileyBlackwell, 2013.

[46] A. Marchand, "Travail et Santé Mentale: Une perspective multi-niveaux des déterminants de la détresse psychologique," Université de Montréal, Montréal, 2004.

[47] A. Marchand, P. Durand, and A. e. Demers, "Un modèle multi-niveaux des déterminants de la santé mentale dans la main-d'oeuvre," Revue Canadienne de Santé Mentale Communautaire, vol. 25, no. 2, pp. 11-30, 2006.

[48] N. Cadieux, "Professions réglementées et détresse psychologique: regards croisés avec la population en emploi au Canada," Universite de Montreal (Canada), 2012.

[49] N. Cadieux, and A. Marchand, "Détresse psychologique chez les professionnels et professionnelles exerçant une profession réglementée: facteurs explicatifs et pistes de réflexion," Canadian Journal of Community Mental Health, vol. 34, no. 3, pp. 15-35, 2015.

[50] V. Hopkins, and D. Gardner, "The mediating role of work engagement and burnout in the relationship between job characteristics and psychological distress among lawyers," New Zealand Journal of Psychology, vol. 41, no. 1, pp. 59-68, 2012.

[51] S. Folkman, "The case for positive emotions in the stress process," Anxiety, stress, and coping, vol. 21, no. 1, pp. 314, 2008.

[52] S. Folkman, "Positive psychological states and coping with severe stress," Social science \& medicine, vol. 45, no. 8, pp. 1207-1221, 1997.

[53] M. Moqbel, and V. Bartelt, "Social Network Sites in Businesses: Combating Technostress", Proceedings of the $51^{s t}$ Hawaii International Conference on System Sciences, pp.1846-1853, 2018.

[54] M. Salo, H. Pirkkalainen, C. Chua, and T. Koskelainen, "Explaining Information Technology Users' Ways of Mitigating Technostress", ECIS 2017 : Proceedings of the $25^{\text {th }}$ European Conference on Information Systems, pp.2460-2476, 2017. Retrieved from http://aisel.aisnet.org/ecis2017_rp/156

[55] A. Ioannou, and A. Papazafeiropoulou, "Using IT Mindfulness to Mitigate the Negative Consequences of Technostress", Twenty-third Americas Conference on Information Systems, Boston, pp. 1-10, 2017. 